\title{
Blood gas analysis syringes containing spray-dosed droplet liquid heparin may decrease sample rejection ratios
}

\author{
๑ $\mathrm{Kamil}$ Taha Uçar ${ }^{1}$, @Nilhan Nurlu ${ }^{2}$ \\ ${ }^{1}$ Bilecik Public Health Laboratory, Medical Biochemistry, Bilecik, Turkey \\ ${ }^{2}$ İstanbul Gaziosmanpaşa Training and Research Hospital, Medical Biochemistry, İstanbul, Turkey
}

Cite this article as: Uçar KT, Nurlu N. Blood gas analysis syringes containing spray-dosed droplet liquid heparin may decrease sample rejection ratios. Anatolian Curr Med J 2021; 3(4); 284-290.

\begin{abstract}
Aim: The objective of this study is to evaluate blood gas analysis (BGA) sample rejection ratios (SRRs) in our laboratory and investigate the effect of various BGA syringes on SRR.

Material and Method: 3 groups were formed based on the type and use period of BGA syringes. Syringes containing spray-dosed droplet liquid Lithium Heparin were used in Group 1 (November 2018-May 2019), syringes containing lyophilized dried Lithium Heparin were used in Group 2 (July 2019-January 2020), and another syringes containing spray-dosed droplet liquid Lithium Heparin were used in Group 3 (March 2020-September 2020), and the groups were determined based on such use. SRRs of these groups were calculated, causes for sample rejection were identified, and department-based investigations were conducted. Comparisons between groups were performed according to the indicated variables.

Results: Mean SRRs of the groups by percentage (\%) were calculated as $6.1 \pm 1.5,10.0 \pm 0.9$, and 3.8 \pm 0.9 , respectively, and showed a statistically significant difference $(\mathrm{p}<0.001)$. Based on the post-hoc Scheffés test, a lower SRR was calculated in Group 3 (P<0.05). The most frequent causes for sample rejection by percentage were found as clotted sample $(73.4 \pm 10.7)$, insufficient sample (14.7 \pm 9.1$)$, and inappropriate (nonconforming) sample (5.5 \pm 2.0$)$. No statistically significant difference was observed based on the causes for sample rejection among the groups. Based on the frequency of SRRs by percentage, the departments were determined as the Emergency Department (ED) (44.3 \pm 11.6$)$, Intensive Care Unit (ICU) (22.2 \pm 6.5$)$, and Pediatric \& Neonatal Emergency Department (PNED) (16.8 \pm 6.6 ). For department-based results among the groups, SRRs for ED and PNED were found to be higher in terms of statistical significance in Group 2 whereas a lower SRR for ICU was determined in Group 3 ( $\mathrm{P}<0.05$ ).

Conclusion: It was observed that BGA syringes containing spray-dosed droplet liquid Lithium Heparin decreased SRRs. Therefore, SRR follow-up may help clinics and laboratories evaluate sample quality as well as developing solutions.
\end{abstract}

Keywords: Blood gas analysis, sample rejection ratio, preanalytical phase, blood collection device, lithium heparin

\section{INTRODUCTION}

Blood gas analysis (BGA) is of vital importance for emergency departments (EDs) and intensive care units (ICUs) as it provides highly accurate results for oxygenation, acid-base equilibrium, and electrolyte levels of patients under life-threatening emergency conditions within a short period $(1,2)$. Fast and accurate results as provided by BGA may allow for faster diagnosis and treatment opportunities (3). Based on the evaluation of the Total Testing Process (TTP) of BGA, it was reported that the most problematic part was the preanalytical (prior to analysis) phase $(1,4)$. In addition to this, it can be concluded that preanalytical phase for BGA is more vulnerable in general and poses a higher threat to patient safety as it often involves sampling and use of analyzers by non-laboratory staff $(5,6)$.
It was reported that sample rejection ratios (SRRs) of BGA particularly in case of use under emergency conditions and for samples received from EDs were higher than those of outpatient/inpatient departments $(7,8)$. Additionally, BGA collection is technically challenging for the phlebotomy staff and may also be painful for the patient from whom the blood sample is collected (9). Therefore, the requirement for resampling in addition to causing a delay in the diagnosis and treatment opportunities in case of BGA sample rejection can be troublesome $(10,11)$. Moreover, other problems such as obtaining inaccurate results or equipment failure may also arise due to lack to identify inappropriate BGA samples (e.g., micro clots, air bubbles, etc.) $(12,13)$. Considering the fact that such equipment is also frequently used by non- 
laboratory staff, e.g., during the quality assessment of samples and equipment maintenance, etc., this process may turn into a difficult challenge for staff who works in an intensive environment under emergency conditions (6). Any failure to provide accurate BGA results in a timely manner may pose a potential threat to patient safety (11). For all such reasons, it is crucial for BGA to use quality indicators (QI), calculate SRRs, and perform routine evaluations (14).

Literature review results in a considerable number of clinical evaluations in relation to BGA. These studies evaluated comparative results among BGA syringes of various manufacturers (15-18), made comparisons between BGA results and clinical biochemical analyzers results $(19,20)$, investigated the effects of preanalytical conditions on clinical results (21) as well as making comparisons among various BGA analyzers $(22,23)$. In addition, the effect of hemolysis on BGA was investigated in particular (24-28). Moreover, quality indicators (QI) and SRRs in relation to BGA were also evaluated in a smaller number of studies $(10,14,29,30)$. It was reported that there was a direct relationship between the sample quality and blood collection devices used, and BGA samples were among the types of samples determined as the most vulnerable to such effect (31). The authors were unable to access any publication in which SRR causes for BGA were investigated in detail, including sample quality assessment in connection with blood collection devices, and discussion of recommendations for solutions.

Our objective in this study is to investigate the TTP for BGA in our laboratory based on SRRs as well as conducting a department-based investigation of SRRs, and a comparison of blood gas analysis (BGA) syringes of various types (i.e., dried, or sprayed liquid lithium heparin) used in the routine procedure in different periods.

\section{MATERIAL AND METHOD}

This observational ambispective study was conducted including BGA samples accepted to the laboratory during the period between November 2018-September 2020 in line with the Declaration of Helsinki (1964) following the approval of the Ethics Committee of Gaziosmanpasa Training and Research Hospital (Date: 31.03.2021, Decision No: 247/2021).

\section{Study Design and Data Collection Process}

Due to a significant increase in BGA SRRs subject to monthly follow-up in our laboratory, it was determined to perform a root cause analysis. For that purpose, the root causes for such an increase in SRRs were investigated and it was found that BGA syringes were replaced. In order to perform a statistical evaluation for such replacement, two separate groups were determined for the previous and the current BGA syringes taking the time of replacement of BGA syringes as the baseline, and SRRs were calculated accordingly. It was determined that BGA syringes used prior to replacement were contained 50 I.U. spray-dosed droplet liquid Lithium Heparin Calcium Balanced/ $\mathrm{ml}$ of blood whereas the new BGA syringes used were contained 72 I.U. lyophilized dried Lithium Heparin Calcium Balanced $/ \mathrm{ml}$ of blood.

Since the most significant cause of the increase in SRRs was determined as the replacement of BGA syringes based on the root cause analysis, BGA syringes were replaced by new syringes. For new ones, syringes that contained 72 I.U. spray-dosed droplet liquid Lithium Heparin Calcium Balanced $/ \mathrm{ml}$ of blood were selected. During the replacement of BGA syringes, the relevant nurses, and authorized staff responsible for blood collection as well as EDs and ICUs were contacted and necessary information on the subject matter was provided accordingly.

Two BGA analyzers are available in our hospital and they are in our emergency laboratory. The selected analyzers consists of two systems, namely, Siemens RAPIDLab 1200 (Siemens Healthcare, Camberley, UK) and Siemens RAPIDPoint 405 (Siemens Healthcare, Camberley, UK). BGA collection and transfer of samples are provided by non-laboratory staff (i.e., physicians, physician residents, and nurses for blood collection, and assigned department staff for transfer of samples) whereas processing of samples as well as the evaluation and reporting of the results were performed by laboratory technicians and specialists. During this period, approximately 5000 BGA samples/month on average were processed in our laboratory. Most of these samples were received from the $\mathrm{ED}$ and the ICU. The samples received by the laboratory mainly contain arterial BGA samples; however, venous BGA samples are preferred in patients at our outpatient clinics. In this study, no differentiation was made for the types of BGA samples collected.

\section{Sample Rejection Causes Evaluation}

As in most of the laboratories in Turkey, our laboratory also follows the recommendations published by the Ministry of Health of the Republic of Turkey for the purpose of SRR evaluation (32). Out of such criteria, the most frequently encountered 10 criteria for sample rejection as applicable to BGA evaluation were listed below:

1. Clotted sample;

2. Insufficient sample;

3. Inappropriate sample (e.g., air bubbles, micro clots, etc.);

4. Blank (empty) sample;

5. Prolonged storage time $(>30 \mathrm{~min}$. at room temperature); 
6. Wrong barcode;

7. Wrong sample container;

8. Rejection resulting from equipment failure;

9. Rejection resulting from laboratory technician failure;

10. Samples delivered under nonconforming transport conditions (e.g., samples coming into any direct contact with ice, samples delivered using pneumatic systems, etc.).

Since BGA syringes were replaced in June 2019, an SRR evaluation vs. Group 2 was conducted as a reference period to ensure that the periods during which the BGA syringes have remained in use were equal. June 2019 was considered as a familiarization period and the monthly SRRs during the period between July 2019 and January 2020 were included in the calculation. Since the second syringes remained in use for 7 months, the evaluation period for Group 1 was determined as the period between November 2018 and May 2019. Finally, February 2020 was considered as a familiarization period since the use of BGA syringes containing spray-dosed droplet liquid lithium heparin was reintroduced in February 2020, and the period between March 2020 and September 2020 was determined as the evaluation period for Group 3.

SRRs of all these groups were obtained from the Laboratory Information System (ALIS, Ventura, Turkey). SRRs, causes for sample rejection, and SRRs based on the departments were calculated. Following the monthly calculation of SRRs, the mean SRRs of the groups were compared against each other. In addition, the causes of sample rejection were also compared among these 3 groups. Finally, department based SRRs were calculated and compared among 3 groups.

\section{Statistical Analysis}

For comparative analysis of the groups, compliance to normal distribution was determined by the ShapiroWilk test. The results were presented in the form of mean \pm standard deviation (SD) since the groups comply with a normal distribution and comparisons among the groups were conducted by the one-way analysis of variance (ANOVA). A post-hoc Scheffés test was conducted to determine differences among the groups since the variances of the groups were equal among such groups. The level of statistical significance was determined as $\mathrm{p}<0.05$ (two-way). Microsoft Office 365 (Microsoft Excel Software, Microsoft Corporation, USA) and MedCalc ${ }^{\circledast}$ Statistical Software version 20 (MedCalc Software Ltd, Ostend, Belgium) software were used to create tables and charts as well as conducting statistical analyses.

\section{RESULTS}

Mean SRRs of 3 groups by percentage (\%) were calculated as $6.1 \pm 1.5,10.0 \pm 0.9$, and $3.8 \pm 0.9$, respectively. The one-way analysis of variance (ANOVA) resulted in a statistically significant difference $(p<0.001)$. Based on the post-hoc Scheffe's test, it was found that each group showed statistically significant differences from one another, and a lower SRR was calculated in Group 3 as compared to other groups (vs. Group $1 \mathrm{p}=0.005$, vs Group $2 \mathrm{p}<0.001)$. The most frequent causes for sample rejection by percentage for each group were found as clotted sample (73.4 \pm 10.7$)$, insufficient

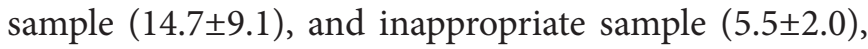
respectively. No statistically significant difference was observed among the causes for sample rejection among the groups with the replacement of BGA syringes. Based on the frequency of SRRs among total SRRs by percentage, the departments were determined as the ED (44.3 \pm 11.6$)$, ICU $(22.2 \pm 6.5)$, and Paediatric \& Neonatal Emergency Department (PNED) (16.8 \pm 6.6$)$, respectively. For department-specific results among the groups, SRRs for ED and PNED were found to be higher in terms of statistical significance in Group 2 (for ED; vs. Group 1 $\mathrm{p}<0.001$, vs Group $3 \mathrm{p}<0.001$, and for PNED; vs. Group $1 \mathrm{p}=0.006$, vs Group $3 \mathrm{p}<0.001$ ) whereas a lower SRR for ICU samples was determined in Group 3 (vs. Group 1 $\mathrm{p}=0.005$, vs Group $2 \mathrm{p}<0.001)$.

Mean SRRs and causes of sample rejection for each group are presented in Table 1, and mean SRRs based on the department-specific are presented in Table 2. Frequencies of sample rejection causes and departments within total SRR based on the frequency of SRR during the evaluation period are found in Figure 1, and Figure 2, respectively. Total SRRs and mean SRR differences among the groups based on causes for sample rejection and departments are illustrated in Figures 3, 4, and 5, respectively.

Table 1. Frequency of sample rejection causes (\%) and total sample rejection ratios (\%) by groups

\begin{tabular}{|ccccccc|}
\hline Groups & Clotted samples & Insufficient samples & Inappropiate samples & Other causes & Total SRR ${ }^{*}(\%)$ \\
\hline 1 & $71.7 \pm 14.5$ & $18.8 \pm 12.1$ & $4.4 \pm 1.9$ & $4.4 \pm 2.8$ & $6.1 \pm 1.5$ \\
3 & $79.4 \pm 5.5$ & $9.88 \pm 2.4$ & $5.7 \pm 2.3$ & $4.4 \pm 2.4$ & $10.0 \pm 0.9$ \\
\hline
\end{tabular}

Data (\%) are presented as mean and SD. Group 1: Between November 2018 and May 2019, used spray-dosed droplet liquid Lithium Heparin BGA syringes, Group 2: Between June 2019 and January 2020, used lyophilized dried Lithium Heparin BGA syringes, and Group 3: Between March 2020 and September 2020, used spray-dosed droplet liquid Lithium

Heparin BGA syringes. SRR: Sample rejection ratio ${ }^{*}$ Total SRRs in 3 groups were found to be statistically significantly different from each other $(\mathrm{p}<0.05)$. 
Table 2. Sample rejection ratios of departments (\%) by groups

\begin{tabular}{|cccc|}
\hline Groups & Emergency department (ED) & Pediatric and neonatal emergency department (PNED) & Intensive care unit (ICU) \\
\hline 1 & $6.0 \pm 2.0$ & $6.3 \pm 1.9$ & $5.2 \pm 1.8$ \\
2 & $13.7 \pm 2.6^{*}$ & $9.5 \pm 1.5^{*}$ & $5.4 \pm 0.4$ \\
3 & $3.9 \pm 1.2$ & $4.6 \pm 1.5$ & $2.6 \pm 1.0^{* *}$ \\
\hline
\end{tabular}

Since the number of samples from other departments was insufficient for data comparison, three departments with the most frequent sample rejection ratios were evaluated. Data (\%) are presented as mean and SD. Group 1: Between November 2018 and May 2019, used spray-dosed droplet liquid Lithium Heparin BGA syringes, Group 2: Between June 2019 and January 2020 us lyophilized dried Lithium Heparin BGA syringes, and Group 3: Between March 2020 and September 2020, used spray-dosed droplet liquid Lithium Heparin BGA syringes *It is statistically significantly higher than the other groups $(\mathrm{p}<0.05)^{* *}$ It is statistically significantly lower than the other groups $(\mathrm{p}<0.05)$

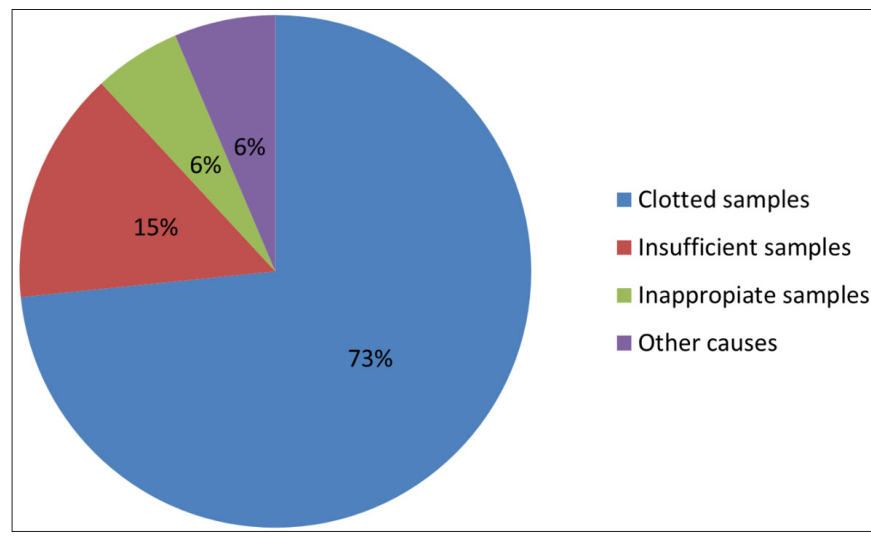

Figure 1. The frequencies (\%) of sample rejection causes

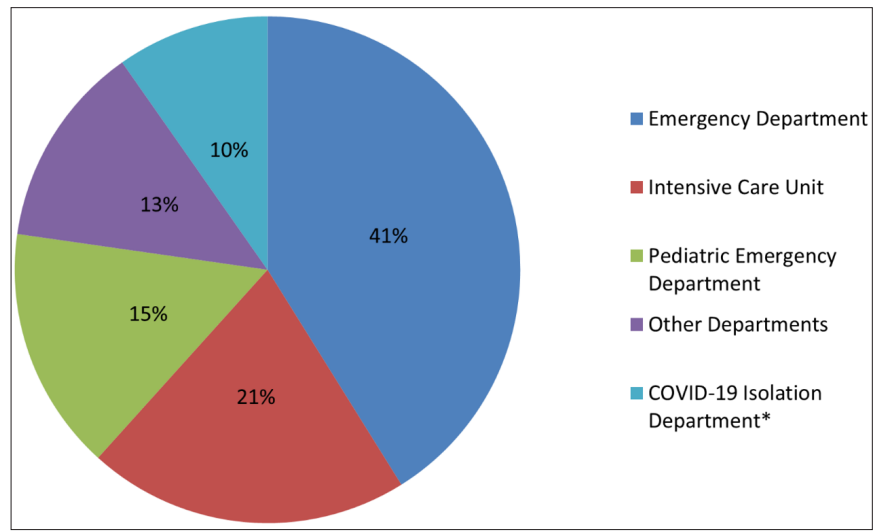

Figure 2. The frequencies (\%) of services sample rejection ratios in total sample rejection ratios.

* The COVID-19 Isolation Department worked only in the 3rd group period.

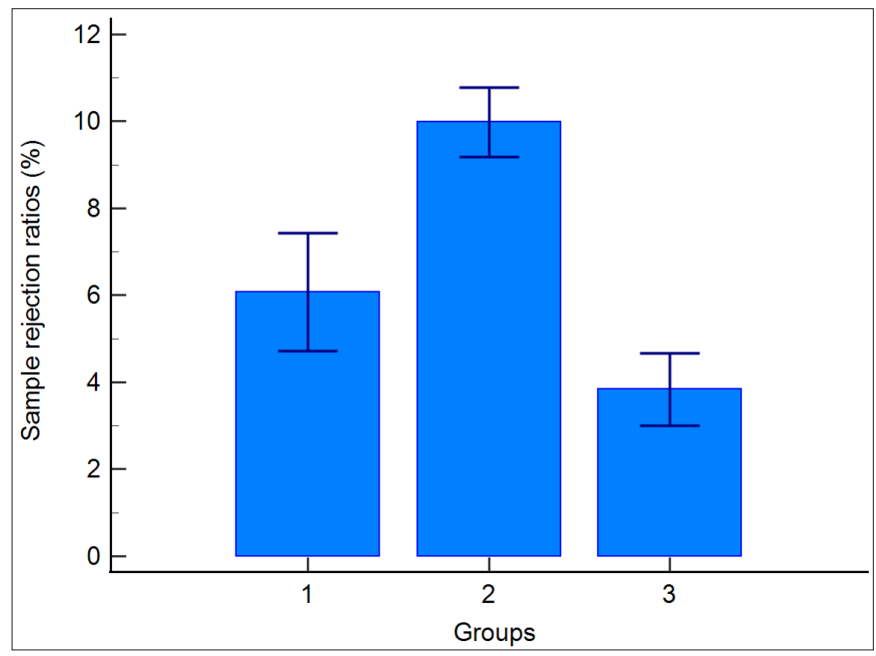

Figure 3. Mean and 95\% CI of total sample rejection ratios (\%) for groups are presented. Group 1: Between November 2018 and May 2019, used spray-dosed droplet liquid Lithium Heparin BGA syringes, Group 2: Between June 2019 and January 2020, used lyophilized dried Lithium Heparin BGA syringes, and Group 3: Between March 2020 and September 2020, used spray-dosed droplet liquid Lithium Heparin BGA syringes.
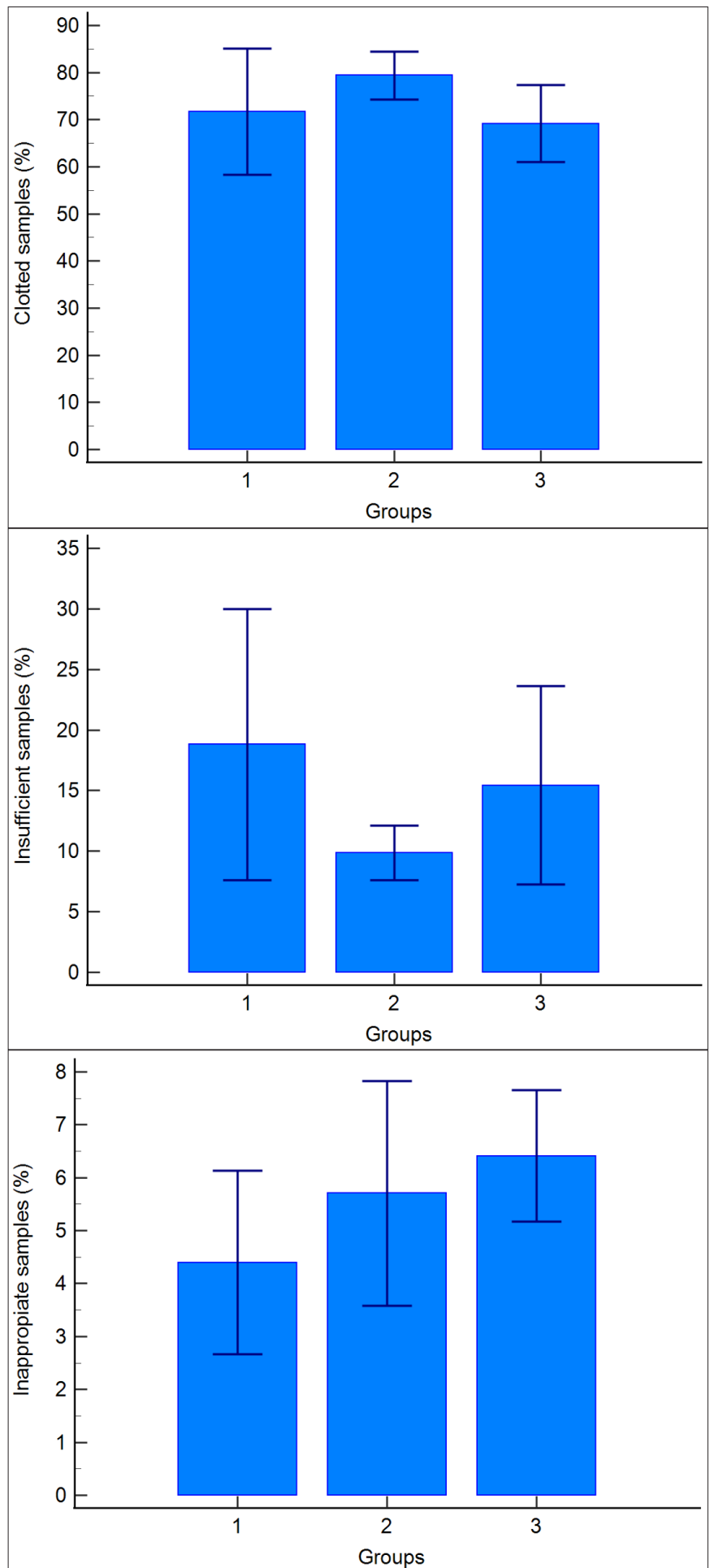

Figure 4. The mean and 95\% CI of the sample rejection ratios (\%) according to the causes in the groups are presented. Group 1: Between November 2018 and May 2019, used spray-dosed droplet liquid Lithium Heparin BGA syringes, Group 2: Between June 2019 and January 2020, used lyophilized dried Lithium Heparin BGA syringes, and Group 3: Between March 2020 and September 2020, used spraydosed droplet liquid Lithium Heparin BGA syringes. 

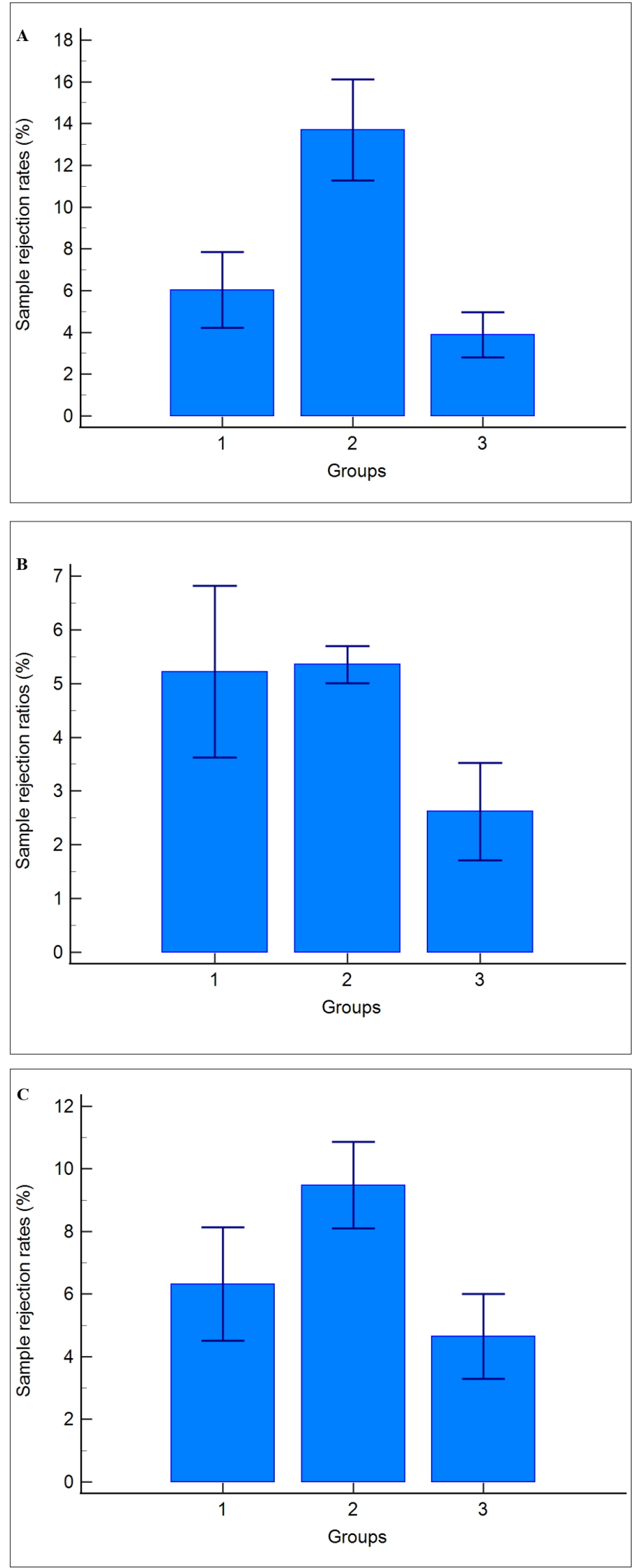

Figure 5. The mean and 95\% CI of the sample rejection ratios (\%) according to the services in the groups are presented. A: Emergency department, B: Intensive care unit, C: Paediatric and Neonatal Emergency department. Group 1: Between November 2018 and May 2019, used spray-dosed droplet liquid Lithium Heparin BGA syringes Group 2: Between June 2019 and January 2020, used lyophilized dried Lithium Heparin BGA syringes, and Group 3: Between March 2020 and September 2020, used spray-dosed droplet liquid Lithium Heparin BGA syringes.

\section{DISCUSSION}

In our study, a decrease in total BGA SRRs with the use of BGA syringes containing spray-dosed droplet liquid Lithium Heparin was indicated. Such a decrease is considered to be associated with the ability of liquid heparin to mix with whole blood much better compared to lyophilized dried heparin. It is assumed that anticoagulant activity in whole blood samples is crucial for sample quality and such activity may be enhanced in line with the ability to mix well with whole blood. On the other hand, no significant difference was found in SRRs in terms of the type of BGA syringes and the causes for sample rejection. As a result of the evaluation of department specific SRRs, a decrease in SRRs for BGA samples received from ED, PNED, and ICU after the replacement of BGA syringes was observed.

Kume et al. (33) found that BGA SRR as $17 \%$ and reported that the most frequent cause for BGA sample rejection consisted of clotted samples. Similarly, during a 1-year SRR follow-up, Dikmen et al. (8) found BGA SRR as $9.2 \%$ and reported that the most frequent two causes of sample rejection were clotted samples and insufficient samples, respectively. In our study, it was indicated that an SRR higher than 10\% was found only in Group 2 and this was in fact associated with the specifications of the BGA syringe. Cantero et al. (14) did not provide any total SRR in their study; however, they found that the sample rejection ratio of the samples rejected due to clotted BGA samples or equipment failure to total accepted samples was $15.8 \%$ for the point-of-care testing (POCT) analyzer in the Neonatal unit and 3.3\% in the Central lab. In addition, they also reported that the ratios for insufficient samples for the two groups were $2.9 \%$ and $0.9 \%$, respectively. Similarly, Oliver et al. (10) did not provide any specific total SRR; however, they reported that BGA SRR specific to each department would be expected to be less than $10 \%$. Accordingly, they reported that only BGA SRRs of the samples received from the Delivery room exceeded $10 \%$ during certain months and the most frequent causes for sample rejection were often associated with the preanalytical phase. Moreno et al. (30) calculated SRRs for BGA samples associated with the preanalytical phase as $2.3-4.2 \%$. In the same study, they indicated that POCT SRRs were higher (Central lab: 2.6\%, POCT: $4.2 \%)$ for the first year, during which SRRs in the Central lab and the POCT in the Nephrology department were evaluated, whereas there was no statistically significant difference between two groups for the second year (Central lab: $2.8 \%$, POCT: $2.3 \%$ ). On the other hand, O'Kane et al. (29) stated that the total SRR for BGA samples was $0.52 \%$ and reported that $77.5 \%$ of this SRR was associated with equipment failures. In our study, the most frequent causes for sample rejection were found as 
clotted, inappropriate, and insufficient samples resulting from preanalytical processes, similar to the findings of the studies except for the study conducted by O'Kane et al. (29) It was assumed that the difference between the findings of O'Kane et al. (29) and our findings was due to the differences between the two studies in terms of the QIs and the method for SRR follow-up.

In fact, there are studies on the follow-up of BGA/POCT processes $(4,5,12,34)$. Nevertheless, a generally accepted quality specification approach is not available since the QIs evaluated in TTP could not be efficiently aligned with BGA/POCT processes (14). For these reasons, it is considered that laboratories may not effectively carry out the follow-up of such processes. Future studies particularly focusing on $\mathrm{BGA} / \mathrm{POCT}$ processes are considered to have the potential to contribute to this area and the safety of patients, physicians, and laboratories in general can be improved as a result. BGA and POCT processes are not exclusively controlled by laboratories (1). For this reason, follow-up, and evaluation of the preanalytical phase, which is the most vulnerable stage of TTP, can be more challenging for BGA and POCT (5). In this context, the organization of activities, symposiums, and work groups, involving other physicians, phlebotomists, and nurses, in addition to the laboratory staff as well as publishing guidelines can be beneficial for the determination of problems and finding possible solutions $(6,13)$.

For the laboratory quality management procedures, all aspects are required to be addressed with an integrated approach (35). Both root cause analysis for sample rejection and clinical evaluations makes a great contribution to finding solutions to the problems (36). At this point, it should not be overlooked that blood collection systems are one of the key variables of this process (37). Blood collection systems and sets should be ergonomic and easy to use with all types of samples and for BGA/POCT samples in particular (1). In this way, it is possible to reduce the number of inappropriate samples causing sample rejection (38). In this context, the European Federation of Clinical Chemistry and Laboratory Medicine (EFLM)-Working Group for Preanalytical Phase (WG-PRE), in an opinion paper, suggested that laboratories should also perform technical evaluations for blood collection systems (39). Especially in smaller laboratories, such technical evaluations may not be possible under routine conditions. The authors suggest that technical evaluations may be carried out using SRR follow-up. A close follow-up for SRRs could significantly contribute to laboratories in the evaluation of sample quality and blood collection systems.

This study had certain restrictions. Firstly, taking into consideration the turnaround time change in the BGA process within the relevant period in addition to calculation and comparison of SRRs as well as technical service and maintenance requirements for BGA analyzer may allow for more accurate results. In addition, since the evaluation of hemolysis in BGA samples is challenging in routine procedure, it was excluded from this study. However, since hemolysis is one of the most frequent causes for inappropriate samples and spurious hemolysis is common especially in BGA samples, it is considered useful to evaluate BGA samples with hemolysis and take necessary steps applicable in routine procedure.

\section{CONCLUSION}

Our study demonstrated that SRRs decreased following the use of syringes containing spray-dosed droplet lithium heparin instead of those containing lyophilized dried lithium heparin. In addition to clinical evaluations, technical evaluations of blood collection systems used may empower laboratories in quality management. Routine SRR follow-up is considered as one of the key tools to help laboratories determine the causes and find solutions for inappropriate/nonconforming samples.

\section{ETHICAL DEVCLARATIONS}

Ethics Committee Approval: To conduct the study, Ethics Committee of Gaziosmanpasa Training and Research Hospital (Date: 31.03.2021, Decision No: 247/2021).

Informed Consent: All patients signed the free and informed consent form.

Referee Evaluation Process: Externally peer-reviewed.

Conflict of Interest Statement: The authors have no conflicts of interest to declare.

Financial Disclosure: The authors declared that this study has received no financial support.

Author Contributions: All of the authors declare that they have all participated in the design, execution, and analysis of the paper, and that they have approved the final version.

\section{REFERENCES}

1. Lippi G, Baird GS, Banfi G, et al. Improving quality in the preanalytical phase through innovation, on behalf of the European Federation for Clinical Chemistry and Laboratory Medicine (EFLM) Working Group for Preanalytical Phase (WGPRE). Clin Chem Lab Med 2017; 55: 489-500.

2. Lippi G, Panteghini M, Bernardini S, et al. Laboratory testing in the emergency department: An Italian Society of Clinical Biochemistry and Clinical Molecular Biology (SIBioC) and Academy of Emergency Medicine and Care (AcEMC) consensus report. Clin Chem Lab Med 2018; 56: 1655-9.

3. Davis MD, Walsh BK, Sittig SE, Restrepo RD. AARC clinical practice guideline: blood gas analysis and hemoximetry: 2013 . Respir Care 2013; 58: 1694-703. 
4. Baird G. Preanalytical considerations in blood gas analysis Biochem Medica 2013; 23: 19-27.

5. Shaw JLV. Practical challenges related to point of care testing. Pract Lab Med 2016; 4: 22-9.

6. Quig K, Wheatley EG, O'Hara M. Perspectives on blood-based point-of-care diagnostics. Open Access Emerg Med 2019; 11: 291-6.

7. Aykal G, Keşapli M, Aydin Ö, et al. Pre-test and post-test applications to shape the education of phlebotomists in a quality management program: An experience in a training hospital. J Med Biochem 2016; 35: 347-53.

8. Gunnur Dikmen Z, Pinar A, Akbiyik F. Specimen rejection in laboratory medicine: Necessary for patient safety? Biochem Medica 2015; 25: 377-85.

9. CLSI. Procedures for the collection of diagnostic blood specimens by Venipuncture; approved standard-sixth edition. CLSI document GP41-A6. Wayne, PA: Clinical and Laboratory Standards Institute; 2007.

10. Oliver P, Fernandez-Calle P, Mora R, et al. Real-world use of key performance indicators for point-of-care testing network accredited by ISO 22870. Pract Lab Med 2020; 22.

11. Lippi G, Betsou F, Cadamuro J, et al. Preanalytical challengestime for solutions. Clin Chem Lab Med 2019; 57: 974-81.

12. Dukić L, Kopčinović LM, Dorotić A, Baršić I. Blood gas testing and related measurements: National recommendations on behalf of the Croatian society of medical biochemistry and laboratory medicine. Biochem Medica 2016; 26: 318-36.

13. Peck Palmer OM, Wheeler SE, Plebani M, Patterson PD, Korpi-Steiner NL, Martin C. Recognition of the prehospital preanalytical phase: collaborative efforts between laboratory medicine and emergency medicine to ensure quality testing. Clin Chem 2020; 66: 998-1005.

14. Cantero M, Redondo M, Martín E, Callejón G, Hortas ML. Use of quality indicators to compare point-of-care testing errors in a neonatal unit and errors in a STAT central laboratory. Clin Chem Lab Med 2015; 53: 239-47.

15. Tang NY, Leanse JH, Tesic V, van Wijk XMR. A comparison of venous blood gas analysis with paired specimens collected in syringes and evacuated blood collection tubes. Clin Chim Acta 2020; 510: 671-4.

16. Uyanik M, Sertoglu E, Kayadibi H, et al. Comparison of blood gas, electrolyte and metabolite results measured with two different blood gas analyzers and a core laboratory analyzer. Scand J Clin Lab Invest 2015; 75: 97-105.

17. Lima-Oliveira G, Lippi G, Salvagno GL, Montagnana M, Picheth G, Guidi GC. Different manufacturers of syringes: A new source of variability in blood gas, acid-base balance and related laboratory test? Clin Biochem 2012; 45: 683-7.

18. Gruber MA, Felbermeir S, Lindner R, Kieninger M. Preanalytics: The (in-)stability of volatile POCT parameters and the homogeneity of blood in syringes at the market. Clin Chim Acta 2016; 457: 18-23.

19. Triplett KE, Wibrow BA, Norman R, et al. Can the blood gas analyser results be believed? A prospective multicentre study comparing haemoglobin, sodium and potassium measurements by blood gas analysers and laboratory auto-analysers. Anaesth Intensive Care 2019; 47: 120-7.

20. Oyaert M, Van Maerken T, Bridts S, Van Loon S, Laverge H, Stove V. Analytical and pre-analytical performance characteristics of a novel cartridge-type blood gas analyzer for point-of-care and laboratory testing. Clin Biochem 2018; 53: 116-26.

21. Küme T, Şişman AR, Solak A, Tuğlu B, Çinkooğlu B, Çoker C The effects of different syringe volume, needle size and sample volume on blood gas analysis in syringes washed with heparin. Biochem Medica 2012; 22: 189-201.

22. Mohammed-Ali Z, Bagherpoor S, et al. Performance evaluation of all analytes on the epoc ${ }^{\circledR}$ Blood Analysis System for use in hospital surgical and intensive care units. Pract Lab Med 2020; 22: $\mathrm{e} 00190$.
23. Chothia MY, Kassum P, Zemlin A. A method comparison study of a point-of-care blood gas analyser with a laboratory autoanalyser for the determination of potassium concentrations during hyperkalaemia in patients with kidney disease. Biochem Medica 2020; 30: 1-7.

24. Salvagno GL, Lippi G, Gelati M, Guidi GC. Hemolysis, lipaemia and icterus in specimens for arterial blood gas analysis. Clin Biochem 2012; 45: 372-3

25. Liu D, Li YX, Huang Y. Analysis of hemolysis, icterus and lipemia in arterial blood gas specimens. Clin Chem Lab Med 2017; 55 e69-71.

26. Lippi G, Ippolito L, Fontana R. Prevalence of hemolytic specimens referred for arterial blood gas analysis. Clin Chem Lab Med 2011; 49: 931-2.

27. Duhalde H, Skogö J, Karlsson M. Point-of-care hemolysis detection in blood gas specimens directly at the emergency department. Scand J Clin Lab Invest 2019; 79: 283-7.

28. Lippi G, Fontana R, Avanzini P, Sandei F, Ippolito L. Influence of spurious hemolysis on blood gas analysis. Clin Chem Lab Med 2013; 51: 1651-4.

29. O'Kane MJ, McManus P, McGowan N, Lynch PLM. Quality error rates in point-of-care testing. Clin Chem 2011; 57: 1267-71.

30. Moreno ALQ, Sáez PO, Calle PF, et al. Clinical, operative, and economic outcomes of the point-of-care blood gases in the nephrology department of a third-level hospital. Arch Pathol Lab Med 2020; 144: 1209-16.

31. Hedberg P, Majava A, Kiviluoma K, Ohtonen P. Potential preanalytical errors in whole-blood analysis: Effect of syringe sample volume on blood gas, electrolyte and lactate values. Scand J Clin Lab Invest 2009; 69: 585-91.

32. Orhan B, Sonmez D, Cubukcu HC, et al. The use of preanalytical quality indicators: a Turkish preliminary survey study. Clin Chem Lab Med 2021; 59: 837-43.

33. Küme T, Ali R, Özkaya A, Çoker C. Preanalytical errors of specimens sent from the emergency department to the laboratory. J Turkish Clin Biochem 2009; 7: 49-55.

34. Dukić L, Šimundić AM. Institutional practices and policies in acid-base testing: A self reported Croatian survey study on behalf of the Croatian society of medical biochemistry and laboratory medicine Working Group for acid-base balance. Biochem Medica 2014; 24: 281-92.

35. Lippi G, Becan-McBride K, Behúlová D, et al. Preanalytical quality improvement: In quality we trust. Clin Chem Lab Med 2013; 51: 229-41

36. West J, Atherton J, Costelloe SJ, Pourmahram G, Stretton A, Cornes M. Preanalytical errors in medical laboratories: a review of the available methodologies of data collection and analysis. Ann Clin Biochem 2017; 54: 14-9.

37. Lima-Oliveira G, Volanski W, Lippi G, Picheth G, Guidi GC Pre-analytical phase management: a review of the procedures from patient preparation to laboratory analysis. Scand J Clin Lab Invest 2017; 77: 153-63.

38. Lippi G, von Meyer A, Cadamuro J, Simundic AM. Blood sample quality. Diagnosis (Berlin, Ger) 2019; 6: 25-31.

39. Lippi G, Cornes MP, Grankvist K, Nybo M, Simundic AM. EFLM WG-Preanalytical phase opinion paper: Local validation of blood collection tubes in clinical laboratories. Clin Chem Lab Med 2016; 54: 755-60. 